\title{
Cellular and molecular basis of cerebellar development
}

\author{
Salvador Martinez ${ }^{1 *}$, Abraham Andreu ${ }^{1}$, Nora Mecklenburg ${ }^{1,2}$ and Diego Echevarria ${ }^{1 *}$ \\ Experimental Embryology Lab, Consejo Superior de Investigaciones Científicas, Instituto de Neurociencias de Alicante, Universidad Miguel Hernandez, \\ Alicante, Spain \\ ${ }^{2}$ Department of Neuroscience, Max-Delbrück-Center for Molecular Medicine, Berlin, Germany
}

\author{
Edited by: \\ José A. Armengol, University Pablo \\ de Olavide, Spain \\ Reviewed by: \\ Isabelle Dusart, Centre National de \\ la Recherche Scientifique, France \\ Mario U. Manto, Fonds de la \\ Recherche Scientifique, Belgium

\section{*Correspondence:} \\ Salvador Martinez and Diego \\ Echevarria, Consejo Superior de \\ Investigaciones Científicas, Instituto \\ de Neurociencias de Alicante, \\ Universidad Miguel Hernandez, \\ Avda. Ramon y Cajal S/N, \\ E03550 Alicante, Spain \\ e-mail:smartinez@umh.es, \\ diegoaza@umh.es
}

Historically, the molecular and cellular mechanisms of cerebellar development were investigated through structural descriptions and studying spontaneous mutations in animal models and humans. Advances in experimental embryology, genetic engineering, and neuroimaging techniques render today the possibility to approach the analysis of molecular mechanisms underlying histogenesis and morphogenesis of the cerebellum by experimental designs. Several genes and molecules were identified to be involved in the cerebellar plate regionalization, specification, and differentiation of cerebellar neurons, as well as the establishment of cellular migratory routes and the subsequent neuronal connectivity. Indeed, pattern formation of the cerebellum requires the adequate orchestration of both key morphogenetic signals, arising from distinct brain regions, and local expression of specific transcription factors. Thus, the present review wants to revisit and discuss these morphogenetic and molecular mechanisms taking place during cerebellar development in order to understand causal processes regulating cerebellar cytoarchitecture, its highly topographically ordered circuitry and its role in brain function.

Keywords: rostral hindbrain, caudal mesencephalon, cerebellum, isthmus, isthmic organizer, isthmic constriction, Fgf8, morphogenesis

\section{INTRODUCTION}

The vertebrate brain is a remarkably complex anatomical structure that contains diverse subdivisions and neuronal subtypes with specific, sometimes prodigal, synaptic connections that contribute to the complexity of its function. During development the primordial brain (the neural tube) has to be progressively regionalized. A precise spatial and temporal arrangement of gene expression regulates intercellular and intracellular signals driving a proper molecular patterning that is required for this regionalization. Pioneering genoarchitectural studies and fate mapping experiments established correlations on how morphogens, transcription factors, and other signaling molecules modulate the specification of neuroepithelial territories, to generate the structural complexity and cellular diversity that characterizes the brain (revised in Puelles and Rubenstein, 2003; Martínez et al., 2012; Puelles and Ferran, 2012). Thus, the combination of molecular genetics (gene expression maps) and modern neuroanatomy (based on histochemistry and highly sensitive neuroimaging) have led to an increased interest in describing the neurodevelopmental mechanisms underlying structural disorders and intellectual discapacities that we currently observe in congenital anomalies of the human brain.

Among the classical systems used to study the structure and function of the central nervous system the cerebellum has steadily gained popularity and has become one of the most experimentally tractable systems in the brain. Much of our knowledge about structure, function, and development of the mouse cerebellum was achieved by studying spontaneous mutations (Sotelo, 2004), but also by using sophisticated genetic tools allowing a more precise and mechanistic level of analysis (Joyner and Sudarov, 2012; Tvrdik and Capecchi, 2012).
This review focuses on the basic developmental biology of the cerebellum starting from morphological features in order to distinguish the origin and specification of the cerebellar neuroepithelial anlage, as well as to describe the molecular mechanisms implicated in the development of its architectural morphology, stereotyped cellular differentiation, and neuronal distribution. Finally, we summarize relevant works in correlations with those findings in developmental cerebellar disorders of the human cerebellum (Barkovich, 2012).

\section{THE TOPOGRAPHY AND TOPOLOGY OF THE CEREBELLAR ANLAGE}

The CNS arises from an apparent homogenous sheet of epithelial cells, the neural plate, induced during gastrulation by the dorsal lip of the blastopore in amphibians (Spemann and Mangold, 1924) or by the Hensen's node in amniotes. During the process of neural induction the neural plate pursues morphological differentiation, its edges thicken and roll up, to close dorsally in order to form the neural tube. The most anterior portion of the neural tube is undergoing drastic changes during early development generating, by differential proliferation, the three primary brain vesicles: the forebrain (prosencephalon), midbrain (mesencephalon), and hindbrain (rhombencephalon); caudal neural tube remains with a cylindrical shape and generates the spinal cord (Martínez and Puelles, 2000). The discovery that putative regulatory genes are expressed in regionally restricted patterns in the developing neural tube has provided new tools for defining histogenic domains and their boundaries at higher resolution. In the rhombencephalon, the segments are termed rhombomeres ( $r$ ) that from anterior to posterior are known as $\mathrm{r} 0$ (the isthmus) and r1-r7, followed by the pseudorhombomeres 
r8-r11 (Marín and Puelles, 1995; Cambronero and Puelles, 2000; Figure 1A). The mature cerebellum is composed of two cerebellar hemispheres and the vermis located between these hemispheres. Embryonically the cerebellar hemispheres and the vermis originate from the first two rhombomeres. The vermis is part of the alar $\mathrm{r} 0$ and roof plates of $\mathrm{r} 0$ and $\mathrm{r} 1$, whereas the hemispheres belong to the alar r1 (Figures 1A, 3A,B). Already in 1890, Wilhelm His proposed the alar neuroepithelium of the anterior rhombencephalon (or metencephalon) as the origin of the cerebellum. He postulated that from these paired plates, the cerebellum evolves as a bilateral organ, which would subsequently fuse at the dorsal roof midline in a rostral-to-caudal direction, to form a uniform primordium.

The topographical boundary between the mesencephalon and rhombencephalon is the isthmic constriction or simply the isthmus (Isth; Figure $\mathbf{1 B}^{\prime}$ ). This was initially interpreted to bridge the midbrain-hindbrain boundary (Alvarado-Mallart, 1993), but is now thought to co-localize with the prospective isthmic territory ( $\mathrm{r} 0)$, as defined early on by the expression of the well-known secreted molecule fibroblast growth factor 8 ( $F g f 8$; Crossley et al., 1996). Homotopic and isochronic quail-chick grafting experiments performed in the late 1980's and the 1990's consistently showed that the caudal part of the early midbrain vesicle had a peculiar morphogenesis and generated the rostral and medial part of the prospective cerebellum (Martinez and Alvarado-Mallart, 1989; Hallonet et al., 1990; Alvarez-Otero et al., 1993; Marin and Puelles, 1994; Hidalgo-Sánchez et al., 2005). Therefore, the anterior vermal part of the presumptive cerebellum, instead to result from fusion of lateral cerebellar plates (His, 1889), originated from the caudal and alar portion of the mesencephalic vesicle. Hence, Puelles and collaborators argued that the early mid-hindbrain constriction observed by Vaage (1969) was not
A
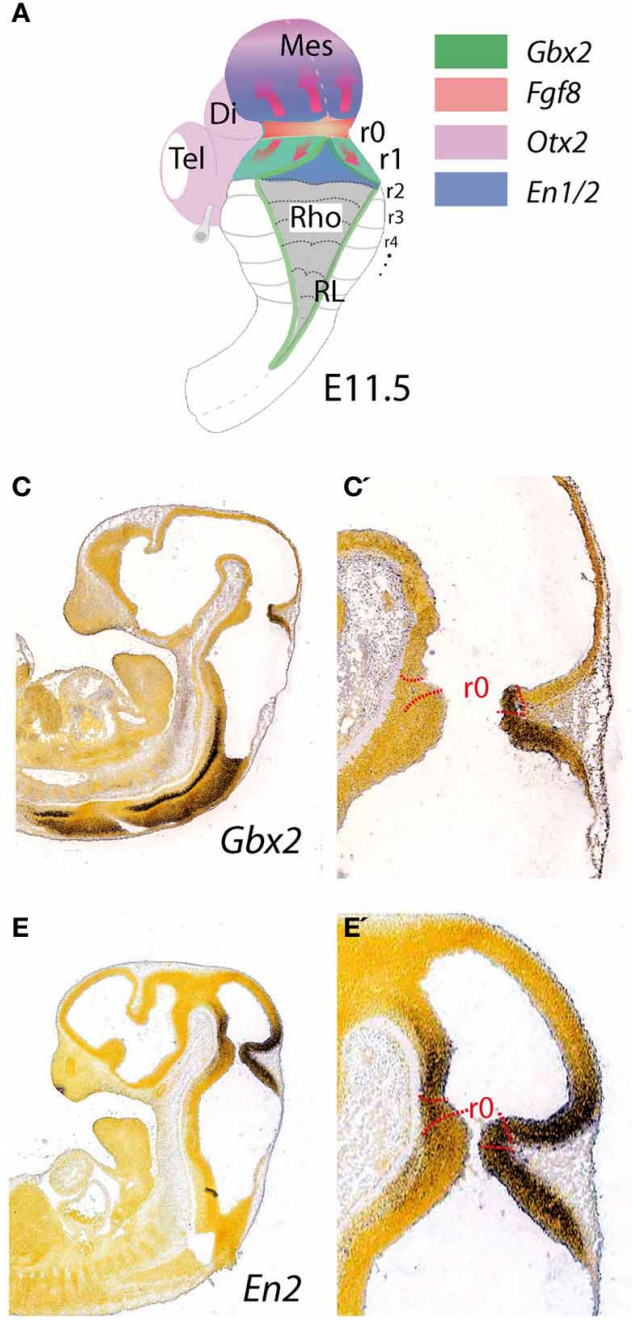

FIGURE 1 | Topographical location and main molecular characterization of the mid-hindbrain boundary at E11.5. (A) A dorsal view of an E11.5 mouse embryo illustrating the isthmic constriction (isth) located between the mesencephalon and rhombomere $1(\mathrm{r} 1)$. Moreover, rhombomeres, $\mathrm{r} 0$ and $\mathrm{r} 1$, which give rise to the cerebellum are highlighted in (A). The different color codes depict the expression pattern of the most important genes related to
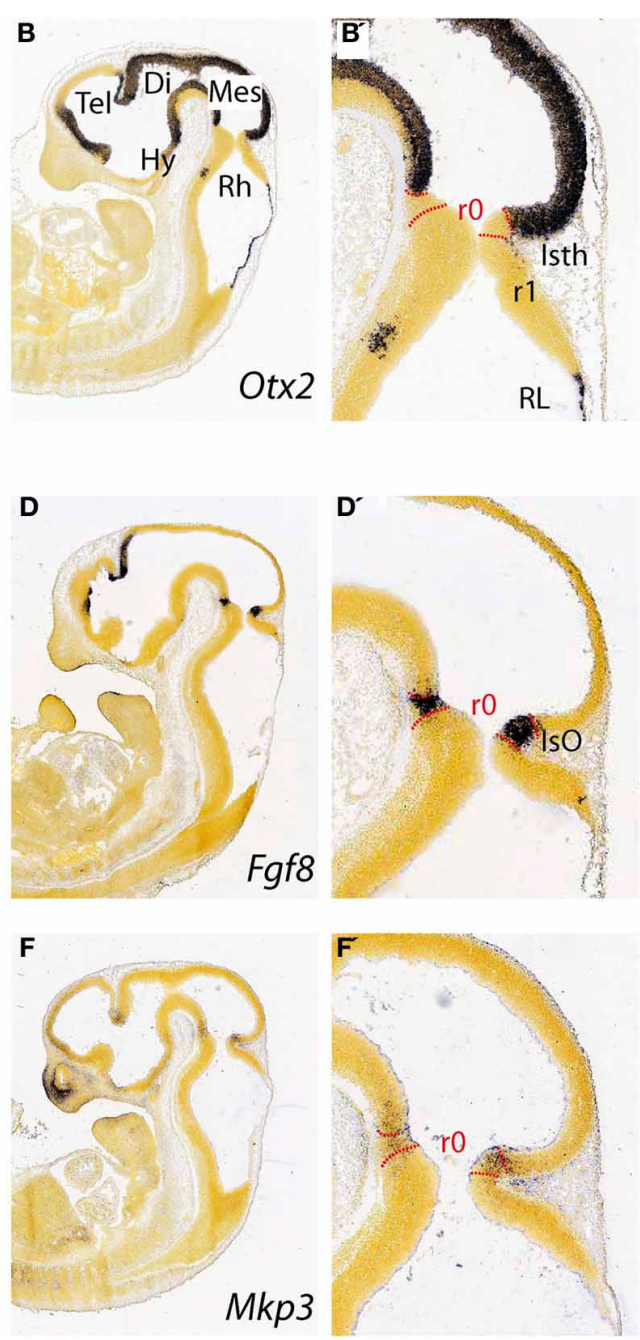

the morphogenetic activity and the capacity of the IsO (We only consider Fgf8-positive territory at this constriction as IsO; see also Martínez, 2001). Expression patterns of genes that are illustrated in (A) and their boundaries are also shown by in situ hybridization (ISH) at E11.5 for Otx2 (B, $\left.\mathbf{B}^{\prime}\right)$, Gbx2 $\left(\mathbf{C}, \mathbf{C}^{\prime}\right)$, Fgf8 (D, $\left.\mathbf{D}^{\prime}\right)$ En2 (E, E'), and Mkp3 (F,F'). Panels (B-F') were taken from Allen Institute for Brain Science public resources (http://www.brain-map.org/) 
a fixed non-proliferative neuroepithelial structure, as proper interneuromeric landmarks are, but it was a wave-like transient conformation of the local proliferating neuroepithelium. In avian embryos gene expression pattern analysis has proved that the relative position of the actual midbrain-hindbrain boundary, is located at the edge of Otx2 and Gbx2 expression domains (initially inside mesencephalic vesicle) and moves caudally after stage $\mathrm{HH} 15$, to coincide with the pre-existent midbrain hindbrain constriction at around HH20-21 (Martinez and Alvarado-Mallart, 1989; Alvarez-Otero et al., 1993; Hidalgo-Sánchez et al., 2005; Figures 1B,C).

The homeodomain transcription factors of Engrailed family En1 and En2 (Figures 1E, $\mathbf{E}^{\prime}$ ) are expressed early on in cerebellar and mesencephalic primordial neuroepithelium and both are involved in the formation of the mesencephalic tectum and cerebellum (Figure 1A). Thus, mouse En1 mutants lack most of the tectum and cerebellum and die at birth, whereas En2 mutants are viable with a smaller cerebellum and foliation defects (Joyner et al., 1991; Hanks et al., 1995). Experimental studies indicate that the severeness of En1 and En2 phenotypes differs due to a relatively early onset of En1 expression compared to the onset of En2 expression, rather than differences in protein function (Joyner et al., 1991; Millen et al., 1995). Studies on conditional mutant alleles of $E n 1$ and/or En2 demonstrated that $E n 1$ is required for cerebellar development only before embryonic day 9, but plays a substantial role in forming the tectum. In fact, En2 was found to be more potent than En1 in cerebellar development (Sgaier et al., 2007). In addition these authors proved that there is an En1/2 dose-dependent genetic subdivision of the tectum into its two functional alar subdivisions (anterior and posterior colliculi) and of the medio-lateral cerebellum into four regions that have distinct molecular coding and represent functional domains.

\section{THE MOLECULAR SPECIFICATION OF THE CEREBELLAR ANLAGE: THE ISTHMIC ORGANIZER}

Distinct neural and glial identities are acquired by neuroepithelial progenitor cells through progressive restriction of histogenetic potential under the influence of local environmental signals. Evidence for morphogenetic regulatory processes at specific locations of the developing neural primordium has led to the concept of secondary organizers, which regulate the identity and regional polarity of neighboring neuroepithelial regions (Ruiz i Altaba, 1998; for review see Echevarría et al., 2003). Thus, these organizers, secondary to those that operate throughout the embryo during gastrulation, usually develop within the previously broadly regionalized neuroectoderm at given genetic boundaries (frequently where cells expressing different transcription factors are juxtaposed). Their subsequent activity refines local neural identities along the AP or DV axes and regionalizing the anterior neural plate and neural tube (Meinhardt, 1983; Figdor and Stern, 1993; Rubenstein and Puelles, 1994; Shimamura et al., 1995; Wassef and Joyner, 1997; Rubenstein et al., 1998; Joyner et al., 2000).

Three regions in the neural plate and tube have been identified as putative secondary organizers: the anterior neural ridge (ANR) at the anterior end of the neural plate, the zona limitans intrathalamica (ZLI) in the diencephalon, and the isthmic organizer ( $\mathrm{IsO}$ ) at the mid-hindbrain boundary (Vieira et al., 2010). Therefore, the isthmic constriction contains the IsO (Figures 1D, $\mathbf{D}^{\prime}$ ), which has been extensively studied during the last decade (Martinez and Alvarado-Mallart, 1989; for review see Martínez, 2001; Wurst and Bally-Cuif, 2001; Echevarría et al., 2003; Aroca and Puelles, 2005; Hidalgo-Sánchez et al., 2005; Nakamura et al., 2005; Partanen, 2007). It is involved in maintaining the mid-hindbrain boundary and providing structural polarity to the adjoining regions in order to orchestrate the complex cellular diversity of the mesencephalon (rostrally) and the cerebellum (caudally; Itasaki and Nakamura, 1992; Martínez, 2001; Rhinn and Brand, 2001; Crespo-Enriquez et al., 2012).

The earliest molecular event for the IsO specification is the differential expression in the neural plate of Otx2 in the rostral epithelium and a $G b \times 2$ in the posterior domain (Wassarman et al., 1997; Shamim and Mason, 1998; Broccoli et al., 1999; Katahira et al., 2000; Figures 1B,C', 4). In the avian embryo at $\mathrm{HH} 8$ an Otx2 and Gbx2 negative neuroepithelial gap separate these domains, but at stages HH9-10 they come to overlap across the prospective mid-hindbrain boundary (Garda et al., 2001). Some of the key experiments, revealing the molecular nature and regulation of the signals for the specification of the $\mathrm{IsO}$, were performed already 18 years ago. A member of the fibroblast growth factor (FGF) family, Fgf8, was found to be highly expressed in the most anterior hindbrain (Heikinheimo et al., 1994; Crossley and Martin, 1995; Figure 1D). Furthermore, beads-containing FGF8 protein were found to effectively mimic the activity of the IsO tissue when transplanted either into the diencephalon or posterior hindbrain (Crossley et al., 1996; Martinez et al., 1999). Since these experiments, members of the FGF8 subfamily (Itoh and Ornitz, 2004) have been shown to be also morphogenetic signals that regulate structural aspects of midbrain, isthmus (Isth), and r1 development (Figures 1A,D, $\mathbf{D}^{\prime}$ ).

Fgf8 expression is first activated at $\mathrm{HH} 9+$ in birds and at E8.5 in mice at the interface of Otx2 and Gbx2 positive neuroepithelial cells. WNT1 and EN2 proteins are already expressed at this stage across the incipient boundary, with a maximum expression level at the $F g f 8$ positive domain, showing decreasing gradients oriented either rostrally toward mesencephalic epithelium or caudally toward rhombencephalic epithelium, respectively. The co-expression of Otx2 and Gbx2 in the IsO territory essentially disappears by HH11-12 and both domains become thereafter mutually excluded and complementary (Millet et al., 1999; Garda et al., 2001; Liu and Joyner, 2001). The caudal limit of Otx2 expression and the rostral limit of Gbx2 therefore mark the mid-hindbrain molecular boundary (MHB; Millet et al., 1996; Hidalgo-Sánchez et al., 1999; Martínez, 2001). Secondarily, $L m \times 1 b$ and Wnt1 are co-expressed in a thin band confined to the caudal most Otx2 expression domain, abutting the Fgf8 domain at the rostral most edge of the hindbrain. $L m x 1 b$ activates $W n t 1$ in a cell-autonomous manner and represses $F g f 8$ in a non-autonomous way, thus contributing to maintain the rostral limit of Fgf8 at the MHB (Matsunaga et al., 2002) and thus being essential for the initial steps of mid-hindbrain development (Guo et al., 2007). Note that although early $F g f 8$ expression appears in the territory co-expressing $O t \times 2 / G b \times 2$, double deletion of these two transcription factors in the mouse does not affect the activation of Fgf8 expression (Li and Joyner, 2001; Martinez-Barbera 
et al., 2001). Other genes expressed at very early stages across the prospective MHB, such as Pax2 (Rowitch and McMahon, 1995; Joyner, 1996; Hidalgo-Sánchez et al., 2005) and Iroquas (Irxs) seem required for the expression of Otx2, Gbx2, and Fgf8 and the proper formation of the mesencephalic and rhombencephalic vesicles (Vieira et al., 2010). Recently it was proposed that $G b \times 2$ and $F g f 8$ are sequentially required for formation of the midhindbrain boundary, playing a crucial role in maintaining here a boundary of cell lineage by restricting cell movement (Sunmonu et al., 2011; Figure 4).

Moreover, FGF8 signal may act at the IsO in concert with other signaling molecules, such as WNT1, Sonic Hedgehog $(\mathrm{SHH})$ and transforming growth factor (TGF)- $\beta$ family members (Danielian and McMahon, 1996; Matsunaga et al., 2002; Vogel-Höpker and Rohrer, 2002; Castelo-Branco et al., 2003; Farkas et al., 2003; Blaess et al., 2006). The morphogenetic activity of the $\mathrm{IsO}$ is then a consequence of a specific temporo-spatial expression of molecular signals, which regulate the specification and structural development of mesencephalic and cerebellar neuroepithelial territories. Alterations of $F g f 8$ and $G b \times 2$ gene expression lead to massive disruption of the mid-hindbrain neural territory by gene patterning dysregulation (Wassarman et al., 1997). A decreasing gradient of FGF8 protein concentration in the alar plate of the isthmus and $\mathrm{r} 1$ is fundamental for cell survival and the differential development of cerebellar regions (Chi et al., 2003; Nakamura et al., 2005; Basson et al., 2008). In the basal plate, FGF8 gradient is crucial for cell survival and, together with $\mathrm{SHH}$, essential for the development of caudal serotonergic and rostral dopaminergic fates of progenitor cells, as well as the localization and development of other basal derivatives, such as noradrenergic cells in the locus coeruleus (in the rhombencephalon) and the red nucleus (in the mesencephalic tegmentum; Wurst and Bally-Cuif, 2001; Chi et al., 2003; Puelles and Rubenstein, 2003; Prakash and Wurst, 2006; Prakash et al., 2006). On the other hand, mesencephalic and diencephalic epithelia are also receptive to FGF8 (Martinez et al., 1991, 1999; Crossley et al., 1996; Crespo-Enriquez et al., 2012), which possibly regulates gene expression and neuroepithelial polarity in the alar plate of these territories (Vieira et al., 2006; Crespo-Enriquez et al., 2012).

Finally, the proposed mechanism by which FGF8 signaling spreads over a field of target cells, at least in zebrafish, is established and maintained by two essential factors: firstly, free diffusion of single FGF8 molecules away from the secretion source through the extracellular space and secondly, an absorptive function of the receiving cells regulated by receptormediated endocytosis (Yu et al., 2009; Nowak et al., 2011; Müller et al., 2013). Several studies have disclosed the position preferences of neuroepithelial cells to FGF8 planar signal activity. The differential orientation and polarity of the FGF8 signal seems to be directly dependent on the spatial position of mouse Fgf8-related secondary organizers and on the activity of the negative modulators, $M k p 3$ (Figures $\mathbf{1 F}, \mathbf{F}^{\prime}$; Echevarria et al., 2005a,b), Sef (Fürthauer et al., 2002; Tsang et al., 2002), and Sprouty1/2 (Spry1/2; Minowada et al., 1999; Echevarria et al., 2005b; Figure 4). Relevant published findings in chick embryos claimed that FGF8b may also translocate into the nucleus, and this nuclear FGF8b could function as a transcriptional regulator to induce Spry2 in the isthmus independently of ERK phosphorylation (Suzuki et al., 2012). Similar findings in mouse found maintenance of Spry2 expression pattern along the Isthmic region in temporally absence of FGF8 in the extracellular compartment, as well as ERK phosphorylation (Crespo-Enriquez et al., 2012). The latter findings reaffirm the existence of positional information encoded by the FGF8 signal through planar transcellular corridors in neuroepithelial cells along the vertebrate neural tube.

\section{HISTOGENESIS AND CELLULAR IDENTITY OF THE CEREBELLAR ANLAGE}

The cerebellum is indeed a unique brain structure dependent of FGF8 signal and Gbx2 homeobox expression. The medial part is know as the vermis and develops from the isthmic and r1 roof plates, while the lateral parts are know as the cerebellar hemispheres and develop from the cerebellar plates at the $\mathrm{r} 1$ alar region (Figures 3A,B; Martinez and Alvarado-Mallart, 1989; Hallonet et al., 1990; Sotelo, 2004; Zervas et al., 2005). The cerebellum is further divided into cortex, white matter, and cerebellar nuclei. The cortex occupies the entire surface and is greatly increased in extension by the characteristic lobulations and foliations, which from a midsagittal section have the appearance of a "tree" (Figure 2E). The cerebellar foliation is consequence of mechanical forces that induce fissure formation (see color-coded folia identification formation in Figures $\mathbf{2 C}-\mathbf{E}$ ). It has been proposed different causal mechanisms for cerebellar foliation: one possibility for folia formation in the cerebellum is because Purkinje cells (PCs) anchors the cortex to the underlying white matter via their axons at positions that define the base of fissures (Altman and Bayer, 1997). Alternatively, differential rates of granule cell precursor proliferation, with highest rates at the base of the fissures, have been suggested to underlie the postnatal growth of folia (Mareš et al., 1970). Recent studies have identified a reproducible series of cellular changes that the three major cerebellar cell types (PCs, granule cells, and Bergmann glia) undergo during initial formation of fissures demonstrating that the timing of these cellular changes governs folial shape (Sudarov and Joyner, 2007). The latter authors proposed a new model for cerebellar cortex folia specification whereby changes in the behavior of granule cell precursors drive the formation of "anchoring centers" at the base of each fissure consisting of PCs, granule cells, and Bergmann glia cells. Then folia outgrowth continues by a self-sustaining process involving the coordinated action of both granule cells and Bergmann glia. En1/2 homeobox genes have been found to be crucial for the production of the distinct medial (vermal) and lateral (hemisphere) foliation patterns in mammalian cerebellum. Thus, these genes are proposed as a new class of genes that are fundamental for patterning cerebellum foliation throughout the medio-lateral axis acting late in development (Cheng et al., 2010; Orvis et al., 2012).

Another interesting aspect of the cerebellar cortex is its quite stereotyped cytoarchitecture. The neuronal subtypes are connected to each other in the same manner, building a cerebellar microcircuit (see below). However, and despite the well-known participation in coordinating proprioceptive-motor processing, the cerebellum is found to be involved in other very important 
A

E11.5

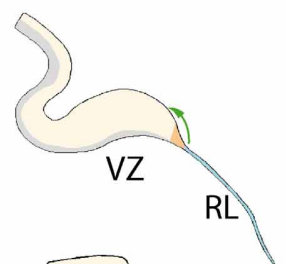

B

E15.5

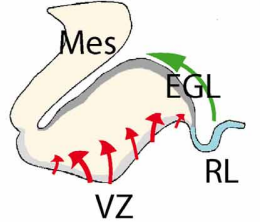

C

E18.5

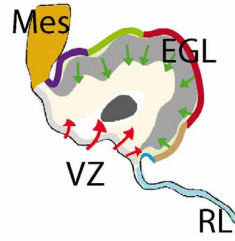

D

P4

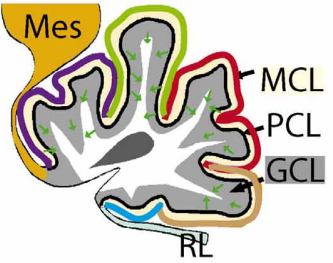

E

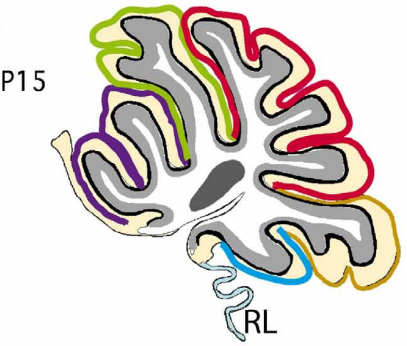

F

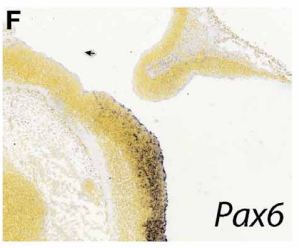

Pax6
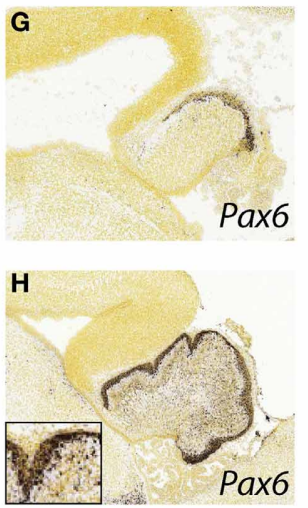

Pax6
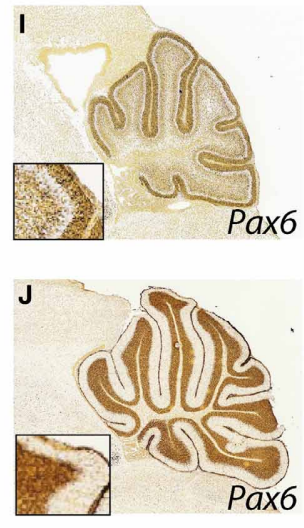

K

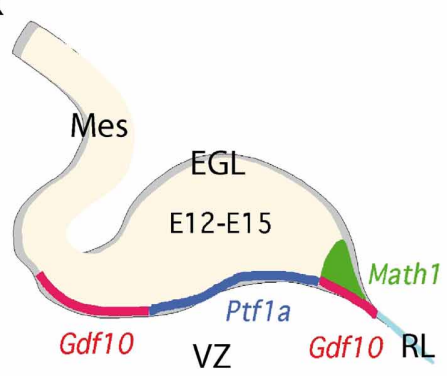

L

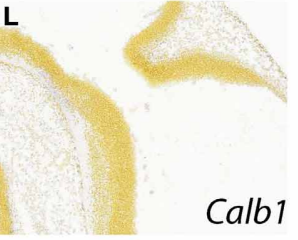

Q

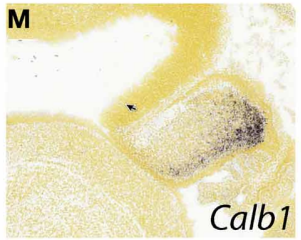

R

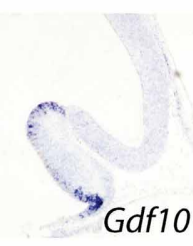

S

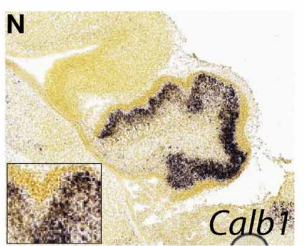

PO

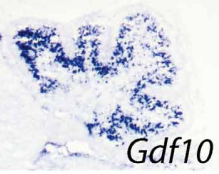

T
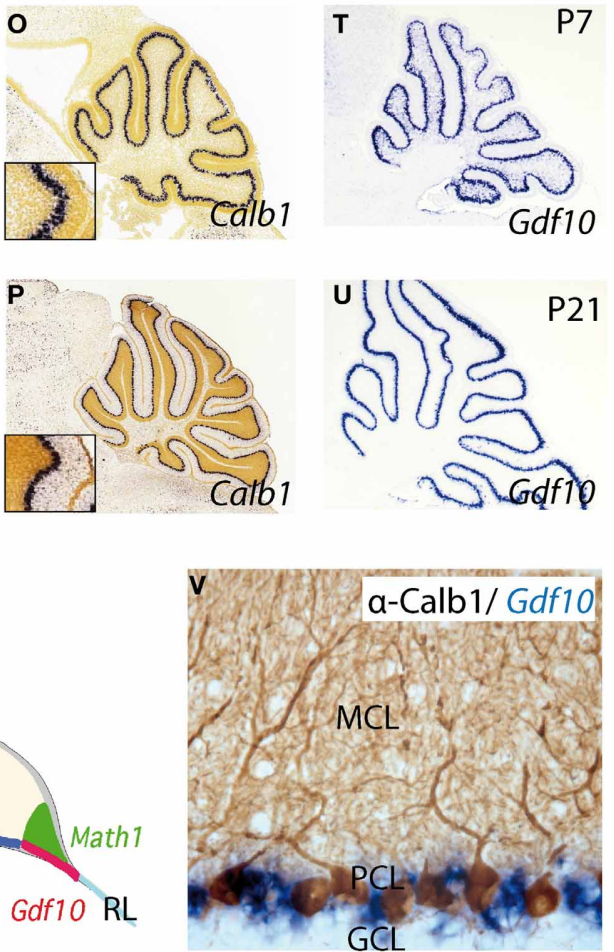

FIGURE 2 | Development of the cerebellum from the rhombencephalic alar plate from early stages to adulthood. (A-E) Cerebellar morphology/anatomy at different stages of development. The cerebellar folia development is showed from E11.5 onwards identifying the corresponding folia primordia bulges as color code lines from rostral to caudal (see also Sudarov and Joyner, 2007). Tangential migration from the rhombic lip (RL) is indicated as a green arrow corresponding to excitatory granule precursor cells that are specified by the expression of Math 1 (K). These cells build up the external granule cell layer and from neonatal stages to P14, they descend radially forming the internal granule cell layer (GCL) located below Purkinje cell layer (PCL). The red arrows highlight the radial migration of cells originating from the ventricular zone (VZ). This is where Purkinje cells (PCs) and GABAergic cells of the cerebellum are born and specified by the early expression of Ptf1a (K); see also Dastjerdi et al.
(2012). (F-U) Represent in situ hybridizations (ISH) of corresponding markers for each cerebellar cell type. Pax6 labeling granule cells $(\mathbf{F}-\mathbf{J})$. From $(\mathbf{H})$ to $(\mathbf{J})$ the insert shows the position of Pax6-positive cells at the EGL and later on, in the GCL (J). In the same manner (L-P) represent Calbindin (Calb1) showing the early location of PCs and their migration from the VZ to the final Purkinje cell monolayer, PCL (see also Sotelo, 2004). (Q-U) shows the expression pattern of Gdf10 (a marker for Bergmann glial cells) by means of ISH during cerebellar development. (V) Here we show the expression of Gdf10 in Bergmann glial cells in adult mice, together with Calbindin- positive Purkinje cells. (K) represents the molecular specification of the different cell types (excitatory vs. inhibitory) in the cerebellum including the two germinal centers ventricular zone (VZ) and rhombic lip (RL). Panels (F-J) and ( $\mathbf{L}, \mathbf{M})$ were taken from Allen Institute for Brain Science public resources (http://www.brain-map.org/). 


\section{A molecular regionalization}

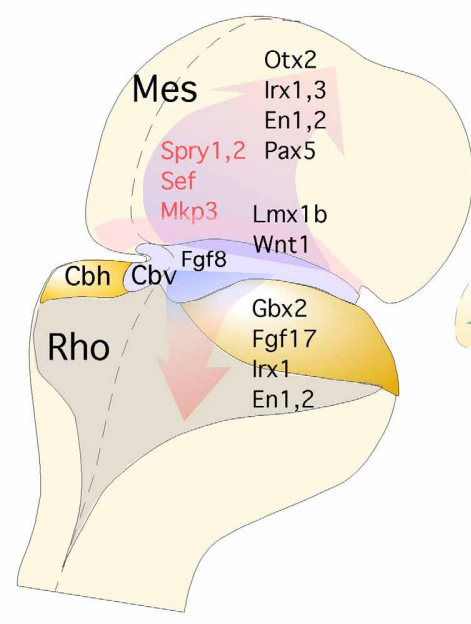

\section{B morphogenetic movements}

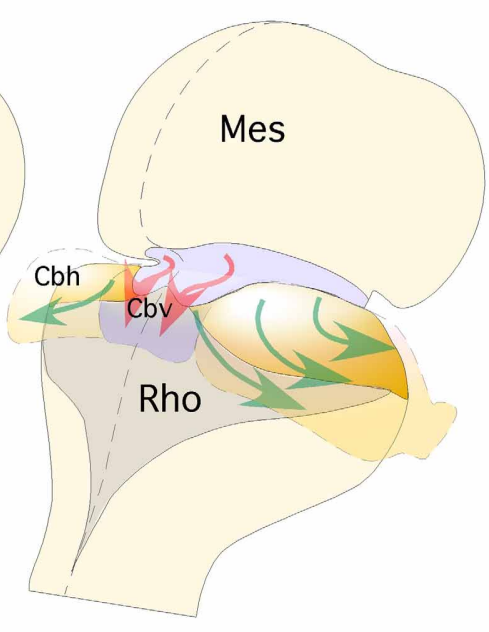

C patterning alterations

(Type I /A,B [Barkovich et al., 2009]): cerebellar/pontine/mesencephalic hypoplasia and posterior fossa disorders

\section{$D$ radial migration (GABAergic neurons)}

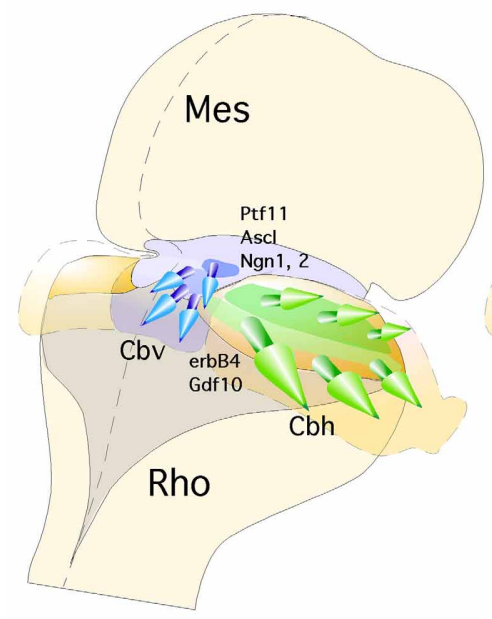

E tangential migration (Glutamatergic neurons)

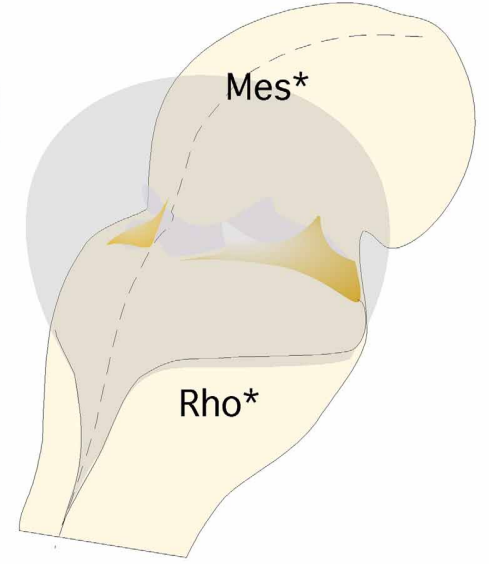

F neuronal proliferation and migration alterations: cerebellar dysgenesis:

(Type II [Barkovich et al., 2009])
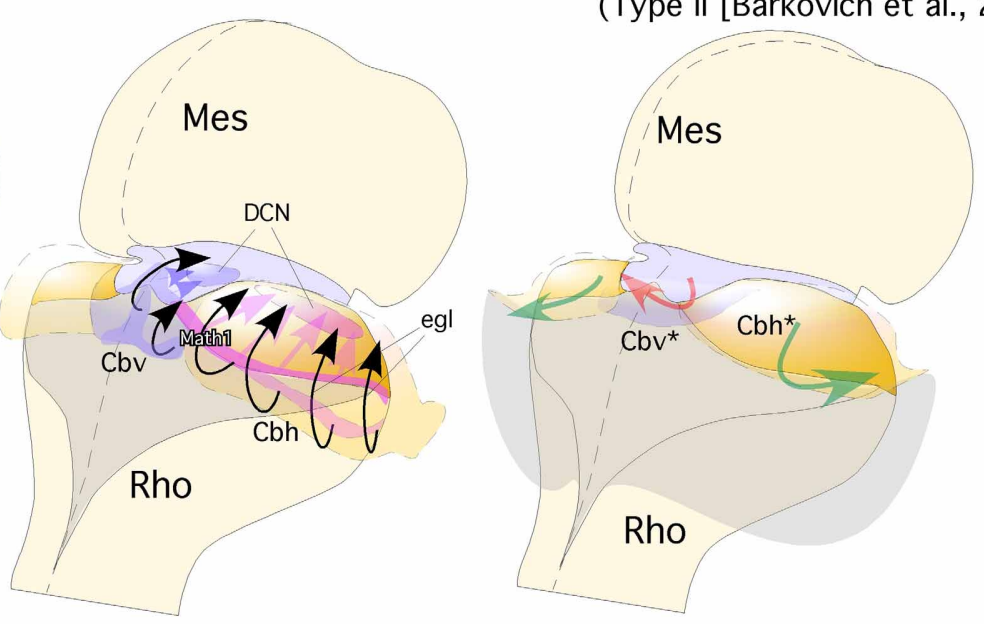

FIGURE 3 | Representation of a dorsal view of mid-hindbrain junction, where the isthmic segment is colored in light purple (which will generate also cerebellar vermis: $\mathrm{Cbv}$ ) and the cerebellar plates in yellow (which will generate cerebellar hemispheres). (A) The isthmic organizer expressing Fgf8 (pink arrows) induces the expression of Sprouty, Sef, and Mkp3 in this region; and is also required for other genes differentially expressed in the midbrain (Mes) or rhombencephalic (Rho) neuroepithelium (B) The spatio-temporal expression of these genes regulates the normal morphogenesis and growth of the cerebellar vermis (Cbv; red arrows) and hemispheres (Cbh; green arrows). (C) Failure in proper isthmic organizer development (due to a lack of morphogenetic signaling or disruption of gene expression) can result in cerebellar (Rho*) and mesencephalic (Mes*) hypoplasia due to a strong increase of cell death with posterior fossa disorders and fourth ventricle dilatation (gray shadow). (D) Radial migration of GABAergic neurons in the cerebellar vermis (Cbv; blue arrows) and hemispheres (Cbh; Green arrows). (E) Rhombic lip specification is regulated by Math 1. Tangential migration of glutamatergic neurons of the deep cerebellar nuclei (DCN) and granule cells (egl) are represented by pink and black arrows, respectively. (F) When normal development of cortical cerebellar cells is disrupted, the structural phenotype is classified as cerebellar dysgenesis ( $\mathrm{Cbv}^{*}$ and $\left.\mathrm{Cbh}^{*}\right)$, with enlargement of the fourth ventricle and reversion of cerebellar-choroidal junction (arrows). higher functions such as cognition, emotion, and language processing (Zervas et al., 2005; Barkovich, 2012).

The adult cerebellar cortex is laminated into three layers. The molecular cell layer (MCL), rich in neuropil consisting mainly of parallel fibers, purkinje dendrites, and glial cell processes as well as neurons allocated at superficial and deep zones, such stellate and basket cells (Figure 2D). The PC layer (PCL) is composed of a monolayer of Calbindin positive PCs (Figures 2D,L-P), 


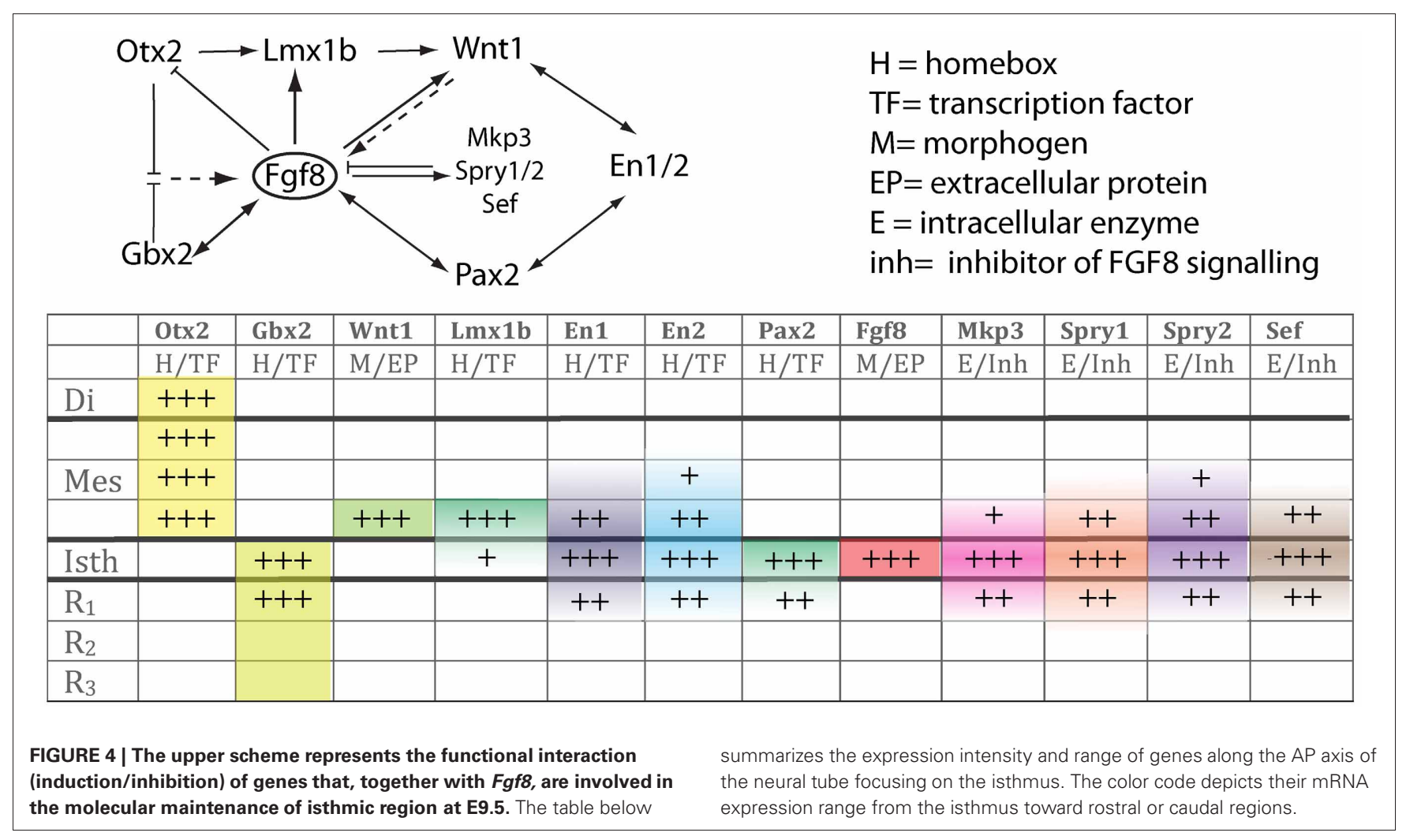

candelabrum cells (Lainé and Axelrad, 1994), and Bergmann glia (see below; Figure 2V). The final and deepest layer is the socalled granule cell layer (GCL) and is the widest cerebellar layer, mainly composed of Pax6 positive granule cells (Figures 2D,F-K) as well as Golgi, Lugaro, and unipolar brush cells (Sotelo, 2004; Zervas et al., 2005). PCs are the only output of the cerebellar cortex, while inputs coming to the granular cells are transmitted to PCs via their axons, the parallel fibers. On the other hand, inhibitory interneurons such as stellate and basket cells innervate dendrites and soma of PCs respectively. Deeply, with respect to the cortex, the white matter is located in the center of the cerebellum. It extends to the ventricular surface of the 4th ventricle, accommodating the cerebellar nuclei (from medial to lateral: the fastigial, the interpositus, and the dentate nucleus). Axons coming from diverse cerebral origins enter the cerebellum through any of the cerebellar peduncles (superior, middle, and inferior). They project either directly or collaterally to the cerebellar nuclei and to the GCL in the cortex, and are named mossy fibers. Only those axons coming from the inferior olive are called climbing fibers because of their "climbing" features to synapses the PC dendrite arborization (Sotelo, 2004).

Neurochemically the cerebellar cortex contains two glutamatergic neuronal subtypes (granule and unipolar brush cells) and five GABAergic subtypes (Purkinje, Golgi, Lugaro, Stellate, and Basket cells). The deep cerebellar nuclei (DCN; Figure 2C), contain both GABAergic interneurons and glutamatergic projection neurons (Wang and Zoghbi, 2001; Hoshino, 2006; Leto et al., 2006; Carletti and Rossi, 2008). Fate-mapping studies of the developing cerebellum have uncovered when and where cells are born and which migratory routes they follow in order to reach their final position. Cerebellar neurons are generated from two major germinal centers: the external granule layer (EGL) and ventricular zone (VZ; Sotelo, 2004; Millen and Gleeson, 2008; Figures 2B,C). Over the past decades has been proven that granule cells are produced by early granule cell precursors located in the EGL that originate from the rhombic lip (RL; Figures 1A,B,, $\mathbf{B}^{\prime}$, 2A-E, 3D,E), at the interface of the dorsal neural tube and the extended roof plate of the 4th ventricle (the choroid plexus; Chp; Wingate, 2001). Also, the glutamatergic DCN neurons and unipolar brush cells are derived from the RL (Fink et al., 2006; Carletti and Rossi, 2008). Therefore, all glutamatergic neurons in the cerebellum appear to originate from the RL. The anterior RL expresses Math1 (also called Atoh1) as early as embryonic stage E9.5 in mice. Math1 is induced by bone morphogenetic protein (BMP) from the roof plate, which itself is differentiating into the Chp (Basson et al., 2008; Figures 2A-E). Math1 positive RL progenitor cells give rise to multiple glutamatergic cell derivatives in a timedependent sequence. Progenitors of the rostral part of the RL migrate through over the cerebellar anlage and give rise to granule progenitors cells and DCN (Figures 3D,E). The caudal part of RL gives rise to multiple brain stem precerebellar nuclei, including the pontine nuclei and superior and inferior olive. Thus, Math1 positive RL cells (Figures 2K, 3E) generate cerebellar granule cells which mature in the EGL and later migrate inwards into the definitive granular cell layer in a anterior to posterior temporal gradient (green arrows in Figures 2A-D, 3D,E; Sotelo, 2004). Unipolar brush cells are the last Math1-positive RL population migrating through the cerebellar white matter to their final GCL 
locations (Millen et al., 1999; Bermingham et al., 2001; Wang et al., 2005; Millen and Gleeson, 2008). Yet, during the first 2 postnatal weeks in mice, granule cell precursors continue differentiating and migrating radially through MCL and PCL layers to form the final internal GCL leaving their bifurcated axons in the MCL (the parallel fibers; Hatten and Heintz, 2005).

The second germinal center, the VZ, has been thought to give rise to cerebellar GABAergic neurons (Altman and Bayer, 1997; Sotelo, 2004; Hoshino, 2006; Sudarov and Joyner, 2007; Carletti and Rossi, 2008; red arrows in Figures 2B,C,K). A recent genetic inducible fate-mapping study demonstrated that dorsal $\mathrm{r} 1$ first undergoes an orthogonal rotation such that the anterior posterior axis (A-P axis) of $\mathrm{r} 1$ at E9.5 becomes the medio-lateral axis (M-L axis) of dorsal r1 at E12.5 (Sgaier et al., 2005; Figure 3B). The M-L axis of ventricular-derived cells is then retained: PCs generated medially are located in the vermis while laterally generated PCs populate the hemispheres (Sgaier et al., 2005, 2007). The pancreas transcription factor 1 (Ptfla), which encodes a bHLH transcription factor, is expressed at the VZ (Figures $2 \mathbf{K}$, 3D; Hoshino et al., 2005; Hoshino, 2006). The characterization of a novel mutant mouse, Cerebelless, which lacks the entire cerebellar cortex but still survives into adulthood, has clarified that Pft1a is required for generating all cerebellar GABAergic neurons including the PCs. Thus, Math1 and Ptfla participate in regionalizing the cerebellar neuroepithelium, and define two distinct territories, the VZ (Ptfla positive) and the upper RL (Math1 positive), which generate GABAergic and glutamatergic neurons, respectively (Hoshino et al., 2005; Pascual et al., 2007; Figures 2K, 3D,E). The earliest markers for GABAergic PC progenitors express Neph3, E-cadherin (Mizuhara et al., 2010) as well as Corl2 (Minaki et al., 2008) in the ventricular and subventricular zone while in post-mitotic PCs neurons other molecular determinants such as Calbindin, is expressed (Figures 2L-P; Sotelo, 2004; Muguruza and Sasai, 2012). Moreover, the expression domains of three pro-neural genes (Ascl1, Neurog1, and Neurog2) overlap with that of Ptfla in the VZ (Zervas et al., 2005; Zordan et al., 2008; Dastjerdi et al., 2012; Figure 3D). A closer analysis of the role of Ascl1 in cerebellar neurogenesis, established that Ascl1 positive progenitors progressively delaminate out of the $\mathrm{VZ}$ to settle first in the prospective white matter, and then in the cerebellar cortex (Grimaldi et al., 2009). These authors demonstrated by gain of function experiments of Ascl1 an increase of Pax2 positive interneurons and Olig2 positive oligodendrocyte precursors, while glutamatergic neurons, astrocytes, and Bergmann glial (BG) cells were not affected. On the other hand, the lack of Ascl1 led to a dramatic reduction of Pax2 and Olig2 precursors. Interestingly, no change was found in PC development in any of the experiments mentioned above. Thus, the latter evidence suggests that Ascll contributes to the generation of GABAergic interneurons and DCN as well as to PC development but not to their specification.

In addition to GABAergic neurons, progenitor cells located in the $\mathrm{VZ}$ of the fourth ventricle also give rise to BG cells. During development, the processes of BG provide structural support to the expanding cerebellar plate (see below). In addition radial Bergmann fibers act as essential guide rails for the migration of granule cells (Rakic, 1990) and contribute to the elaboration of
PC dendrites (Yamada et al., 2000) and stabilize synaptic connections onto these neurons (Iino et al., 2001). Indirect evidence suggests that neuregulin, a member of the epidermal growth factor family, and its membrane receptor erbB4 are involved in the cerebellar induction of the radial glial scaffolds for granule cell migration (Rio et al., 1997). Migrating granule cells, as well as their EGL precursors (green arrows in Figures 2A-D), express neuregulin, whereas Bergmann fibers express erbB4 in the postnatal cerebellum. Moreover, activation of the receptor with soluble neuregulin mimics the effects of neuron-radial glial interactions in the induction of radial glial formation. In contrast, when the glial erbB4 receptors are inactivated by transfection with a dominant-negative form of erbB4, granule cells and soluble neuregulin fail to induce the radial glial phenotype in vitro (Rio et al., 1997).

BG cells, like interneurons and PCs, are born in the VZ of the fourth ventricle, where they express among other lineagerestricted markers growth and differentiation factor 10 (Gdf10; Figures 2Q-V; Alcaraz et al., 2006; Koirala and Corfas, 2010). In mice $G d f 10$ was identified as a marker expressed in the PCL of the cerebellum (Zhao et al., 1999). Based on a publication by Zhao and colleagues, Gdf10 is expressed in PCL but not in GCL. Finally, it was further demonstrated that Gdf10 is expressed in BG cells (Koirala and Corfas, 2010). Gdf10 localizes to the cerebellar VZ as early as E13.5 and by E15.5, Gdf10-positive cells actively migrate toward the pial surface, as part of a migration process that these cells undergo until postnatal day P7 (Yamada and Watanabe, 2002). From P7 onwards Gdf10 expression in the PCL becomes progressively more restricted to fine band of BG cells located between the soma of Purkinje neurons (Figures 2U,V). Our knowledge of possible interaction partners of Gdf10 is very limited and Gdf10 null mutant mice develop normally (Zhao et al., 1999). However, in PC degeneration mice (pcd3J) Gdf10 is reduced to $15 \%$ of the signal obtained from wild type littermates of the same age ( 4 postnatal months; Rong et al., 2004).

\section{HUMAN CEREBELLAR DISORDERS RELATED TO DEFECTS AT THE ISTHMIC ORGANIZER}

As we mentioned above, the cerebellum and its stereotyped circuitry, contributes not only to motor learning and correction of motor acts, but also to cognitive and emotional functions. Clumsiness and abnormal motor behavior have been welldocumented in disorders such as autism and Asperger's syndrome (see Frith, 1991; Fatemi et al., 2012; Rogers et al., 2013), in dyslexia (Nicolson et al., 2001) and in schizophrenia (Owens et al., 1982). The cerebellum is ontogenetically and functionally heterogeneous, with cerebellar zones from different precursor domains ( $\mathrm{r} 0 / \mathrm{r} 1$ vermis or $\mathrm{r} 1$ cerebellar hemispheres) selectively interconnecting with different cerebral subsystems. In addition, the main cellular and molecular processes in cerebellar histogenesis are regulated by the same morphogenetic signals operating in other brain regions (Airey et al., 2001; Echevarría et al., 2003; Vieira et al., 2010; Figures 3A,B). Thus, it is not surprising to find developmental disorders that affect both different functional systems in the forebrain and the cerebellum. Advances in developmental genetics, neurobiology, molecular 
biology, and neuroimaging have led to a better understanding of developmental disorders arose from the embryonic midbrain and hindbrain, (Barkovich et al., 2007, 2009). Although malformations of the hindbrain maybe the only recognized abnormality in individuals with mental retardation or autism (Soto-Ares et al., 2003; Courchesne et al., 2005), they are more commonly associated with malformations of the cerebrum. A contribution to our incomplete knowledge of the clinical consequences of hindbrain and cerebellar anomalies may be due to intrinsic difficulties in neuroimaging and anatomical complexity of the cerebral region.

The combination of a shortened midbrain and/or elongated pons is associated with an enlarged anterior vermis in humans presumably due to a rostral displacement of the $\mathrm{IsO}$, with loss of mesencephalic tissue and gain of cerebellar tissue (Figure 3C). In fact, this malformation is presumed to result from $G B X 2$ predominance over OTX2 and a consequent rostral shift of the IsO (Chizhikov and Millen, 2003; Barkovich et al., 2009). In the counterpart of this phenotype, Ballabio and co-workers (Quaderi et al., 1997) described opposite phenotype in the Opitz G/BBB syndrome (OS), a X-linked genetic anomaly that is caused by a loss of function of the MID1 gene. Neuroimaging of human brain patients lacking this gene showed hypoplasia of the anterior cerebellar vermis (Pinson et al., 2004; Fontanella et al., 2008;

\section{REFERENCES}

Airey, D. C., Lu, L., and Williams, R. W. (2001). Genetic control of the mouse cerebellum: identification of quantitative trait loci modulating size and architecture. J. Neurosci. 21, 5099-5109.

Alcaraz, W. A., Gold, D. A., Raponi, E., Gent, P. M., Concepcion, D., and Hamilton, B. A. (2006). Zfp423 controls proliferation and differentiation of neural precursors in cerebellar vermis formation. Proc. Natl. Acad. Sci. U.S.A. 103, 19424-19429. doi: 10.1073/pnas.0609184103

Altman, J., and Bayer, S. A. (1997). Development of the Cerebellar System in Relation to its Evolution, Structure and Functions. New York, NY: CRC Press.

Alvarado-Mallart, R. M. (1993). Fate and potentialities of the avian mesencephalic/metencephalic neuroepithelium. J. Neurobiol. 24, 1341-1355. doi: 10.1002/neu.480 241007

Alvarez-Otero, R., Sotelo, C., and Alvarado-Mallart, R. M. (1993). Chick/quail chimeras with partial cerebellar grafts: an analysis of the origin and migration of cerebellar cells. J. Comp. Neurol. 333, 597-615. doi: 10.1002/cne.903330411

Aroca, P., and Puelles, L. (2005). Postulated boundaries and differential fate in the developing rostral hindbrain. Brain Res. Brain Res. Rev. 49, 179-190. doi: 10.1016/j.brainresrev.2004.12.031
Barkovich, A. J. (2012). Developmental disorders of the midbrain and hindbrain. Front. Neuroanat. 6:7. doi: 10.3389/fnana.2012.00007

Barkovich, A. J., Millen, K. J., and Dobyns, W. B. (2007). A developmental classification of malformations of the brainstem. Ann. Neurol. 62, 625-639. doi: 10.1002/ana.21239

Barkovich, A. J., Millen, K. J., and Dobyns, W. B. (2009). A developmental and genetic classification for midbrain-hindbrain malformations. Brain 132, 3199-3230. doi: 10.1093/brain/awp247

Basson, M. A., Echevarria, D., Ahn, C. P., Sudarov, A., Joyner, A. L., Mason, I. J., et al. (2008). Specific regions within the embryonic midbrain and cerebellum require different levels of FGF signaling during development. Development 135, 889-898. doi: 10.1242/dev.011569

Bermingham, N. A., Hassan, B. A., Wang, V. Y., Fernandez, M., Banfi, S., Bellen, H. J., et al. (2001). Proprioceptor pathway development is dependent on Math1. Neuron 30, 411-422. doi: $\quad 10.1016 /$ S0896-6273(01) 00305-1

Blaess, S., Corrales, J. D., and Joyner, A. L. (2006). Sonic hedgehog regulates Gli activator and repressor functions with spatial and temporal precision in the mid/hindbrain region. Development 133, 1799-1809. doi: 10.1242/dev.02339

Figures 3C,F). Concomitantly, Mid1-null mice show also vermis hypoplasia among other motor coordination defects (Lancioni et al., 2010). In these mice a rostralization of the mid-hindbrain constriction occurs together with a down-regulation of Fgf17, an important signal during the morphogenetic activity of the IsO (Xu et al., 2000; Zanni et al., 2011). Thus, the increasing of knowledge in basic embryology, genetics, and in cellular and molecular biology of the developing brain must be emphasized to prove the importance in recognizing, understanding, and classifying anomalies in human pathologies (Barkovich, 2012).

\section{ACKNOWLEDGMENTS}

This work was supported by the following Grants: European Consortium: EUCOMMTOOLS (Contract 261492), Friedreich's Ataxia Research Alliance (FARA), the Spanish Ministry of Science and Innovation: FEDER (BFU-2011-27326) and CONSOLIDER (CSD2007-00023), Institute of health Carlos III: Red TERCEL (RD06/001/0023 and RD12/0019/0024), Generalitat Valenciana: PROMETEO (2009/028) and Spanish Foundations: Fundación Síndrome 5p-, Asociación Walk on Project (WOP), Asociación Granadina de Ataxia de Friedrich (ASOFAG), Fundación Diógenes, and Fundación MAPFRE.

Broccoli, V., Boncinelli, E., and Wurst, W. (1999). The caudal limit of Otx2 expression positions the isthmic organizer. Nature 40, 164-168. doi: $10.1038 / 43670$

Cambronero, F., and Puelles, L. (2000). Rostrocaudal nuclear relationships in the avian medulla oblongata: a fate map with quail chick chimeras. J. Comp. Neurol. 427, 522-545. doi: 10.1002/1096-9861(20001127)427: $4<522:$ :AID-CNE3>3.0.CO;2-Y

Carletti, B., and Rossi, F. (2008). Neurogenesis in the cerebellum. Neuroscientist 14, 91-100. doi: $10.1177 / 1073858407304629$

Castelo-Branco, G., Wagner, J., Rodriguez, F. J., Kele, J., Sousa, K., Rawal, N., et al. (2003). Differential regulation of midbrain dopaminergic neuron development by Wnt-1, Wnt-3a, and Wnt-5a. Proc. Natl. Acad. Sci. U.S.A. 100, 12747-12752. doi: 10.1073/pnas.1534900100

Cheng, Y., Sudarov, A., Szulc, K. U., Sgaier, S. K., Stephen, D., Turnbull, D. H., et al. (2010). The Engrailed homeobox genes determine the different foliation patterns in the vermis and hemispheres of the mammalian cerebellum. Development 137, 519-529. doi: 10.1242/dev. 027045

Chi, C. L., Martinez, S., Wurst, W., and Martin, G. R. (2003). The Isthmic organizer signal FGF8 is required for cell survival in the prospective midbrain and cerebellum.
Development 130, 2633-2644. doi: 10.1242/dev.00487

Chizhikov, V., and Millen, K. J. (2003). Development and malformations of the cerebellum in mice. Mol. Genet. Metab. 80, 54-65. doi: 10.1016/j.ymgme.2003.08.019

Courchesne, E., Redcay, E., Morgan, J. T., and Kennedy, D. P. (2005). Autism at the beginning: microstructural and growth abnormalities underlying the cognitive and behavioral phenotype of autism. Dev. Psychopathol. 17, 577-597. doi: 10.1017/ S0954579405050285

Crespo-Enriquez, I., Partanen, J., Martinez, S., and Echevarria, D. (2012). Fgf8-related secondary organizers exert different polarizing planar instructions along the mouse anterior neural tube. PLOS ONE 7:e39977. doi: 10.1371/journal.pone.0039977

Crossley, P. H., and Martin, G. R. (1995). The mouse Fgf8 gene encodes a family of polypeptides and is expressed in regions that direct outgrowth and patterning in the developing embryo. Development 121, 439-451.

Crossley, P. H., Martinez, S., and Martin, G. R. (1996). Midbrain development induced by FGF8 in the chick embryo. Nature 380, 66-68. doi: 10.1038/380066a0

Danielian, P. S., and McMahon, A. P. (1996). Engrailed-1 as a target of the Wnt-1 signalling pathway in 
vertebrate midbrain development. Nature 383, 332-334. doi: 10.1038/ 383332a0

Dastjerdi, F. V., Consalez, G. G., and Hawkes, R. (2012). Pattern formation during development of the embryonic cerebellum. Front. Neuroanat. 6:10. doi: 10.3389/fnana.2012.00010

Echevarria, D., Martinez, S., Marques, S., Lucas-Teixeira, V., and Belo, J. A. (2005a). Mkp3 is a negative feedback modulator of Fgf8 signaling in the mammalian isthmic organizer. Dev. Biol. 277, 114-128. doi: 10.1016/j.ydbio.2004.09.011

Echevarria, D., Belo, J. A., and Martinez, S. (2005b). Modulation of FGF8 activity during vertebrate brain development. Brain Res. Brain Res. Rev. 49, 150-157. doi: 10.1016/j.brainresrev.2004.12.035

Echevarría, D., Vieira, C., Gimeno, L., and Martínez, S. (2003). Neuroepithelial secondary organizers and cell fate specification in the developing brain. Brain Res. Brain Res. Rev. 43, 179-191. doi: 10.1016/j.brainresrev.2003.08.002

Farkas, L. M., Dünker, N., Roussa, E., Unsicker, K., and Krieglstein, K. (2003). Transforming growth factor-beta(s) are essential for the development of midbrain dopaminergic neurons in vitro and in vivo. J. Neurosci. 23, 5178-5186.

Fatemi, S. H., Aldinger, K. A., Ashwood, P., Bauman, M. L., Blaha, C. D., Blatt, G. J., et al. (2012). Consensus paper: pathological role of the cerebellum in autism. Cerebellum 11, 777-807. doi: 10.1007/s12311-0120355-9

Figdor, M. C., and Stern, C. D. (1993). Segmental organization of embryonic diencephalon. Nature 363, 630-634. doi: 10.1038/ 363630a0

Fink, A. J., Englund, C., Daza, R. A., Pham, D., Lau, C., Nivison, M., et al. (2006). Development of the deep cerebellar nuclei: transcription factors and cell migration from the rhombic lip. J. Neurosci. 26, 3066-3076. doi: 10.1523/ JNEUROSCI.5203-05.2006

Fontanella, B., Russolillo, G., and Meroni, G. (2008). MID1 mutations in patients with X-linked Opitz G/BBB syndrome. Hum. Mutat. 29, 584-594. doi: 10.1002/humu.20706

Frith, U. (1991). Autism and Asperger's Syndrome. London: Cambridge University Press. doi: 10.1017/ СВО9780511526770

Fürthauer, M., Lin, W., Ang, S. L., Thisse, B., and Thisse, C. (2002). Sef is a feedback-induced antagonist of Ras/MAPK-mediated FGF signalling. Nat. Cell Biol. 4, 170-174. doi: 10.1038/ncb750

Garda, A. L., Echevarría, D., and Martínez, S. (2001). Neuroepithelial co-expression of Gbx2 and Otx2 precedes Fgf8 expression in the isthmic organizer. Mech. Dev. 101, 111-118. doi: 10.1016/S0925-4773(00)00567-0

Grimaldi, P., Parras, C., Guillemot, F., Rossi, F., and Wassef, M. (2009). Origins and control of the differentiation of inhibitory interneurons and glia in the cerebellum. Dev. Biol. 328, 422-433. doi: 10.1016/j.ydbio.2009.02.008

Guo, C., Qiu, H. Y., Huang, Y., Chen, H., Yang, R. Q., Johnson, R. L., et al. (2007). Lmxlb is essential for Fgf8 and Wntl expression in the isthmic organizer during tectum and cerebellum development in mice. Development 134, 317-325. doi: 10.1242/dev.02745

Hallonet, M. E., Teillet, M. A., and Le Douarin, N. M. (1990). A new approach to the development of the cerebellum provided by the quailchick marker system. Development 108, 19-31.

Hanks, M., Wurst, W., AnsonCartwright, L., Auerbach, A. B., and Joyner, A. L. (1995). Rescue of the En-1 mutant phenotype by replacement of En-1 with En-2. Science 269, 679-682. doi: $10.1126 /$ science.7624797

Hatten, M. E., and Heintz, N. (2005). Large-scale genomic approaches to brain development and circuitry. Annu. Rev. Neurosci. 28, 89-108. doi: 10.1146/ annurev.neuro.26.041002.131436

Heikinheimo, M., Lawshé, A., Shackleford, G. M., Wilson, D. B., and MacArthur, C. A. (1994). Fgf-8 expression in the postgastrulation mouse suggests roles in the development of the face, limbs and central nervous system. Mech. Dev. 48, 129-138. doi: 10.1016/0925-4773(94)90022-1

Hidalgo-Sánchez, M., Millet, S., BlochGallego, E., and Alvarado-Mallart, R. M. (2005). Specification of the meso-isthmo-cerebellar region: the Otx2/Gbx2 boundary. Brain Res. Brain Res. Rev. 49, 134-149. doi: 10.1016/j.brainresrev.2005.01.010

Hidalgo-Sánchez, M., Simeone, A., and Alvarado-Mallart, R. M. (1999). Fgf8 and Gbx2 induction concomitant with Otx2 repression is correlated with midbrain-hindbrain fate of caudal prosencephalon. Development 126, 3191-3203.

His, W. (1889) Vorschlage zur inteilung des Gehirns. Arch. Anat. Entiwicklungsgesch. 17, 172-179.
Hoshino, M. (2006). Molecular machinery governing GABAergic neuron specification in the cerebellum. Cerebellum 5, 193-198. doi: 10.1080/14734220600589202

Hoshino, M., Nakamura, S., Mori, K., Kawauchi, T., Tera, oM. Nishimura, Y. V., et al. (2005) Ptfla, a bHLH transcriptional gene, defines GABAergic neuronal fates in cerebellum. Neuron 47, 201-213. doi: 10.1016/j.neuron. 2005.06.007

Iino, M., Goto, K., Kakegawa, W., Okado, H., Sudo, M., Ishiuchi, S. et al. (2001). Glia-synapse interaction through $\mathrm{Ca} 2+$-permeable AMPA receptors in Bergmann glia. Science 292, 926-929. doi: 10.1126/science. 1058827

Itasaki, N., and Nakamura, H. (1992). Rostrocaudal polarity of the tectum in birds: correlation of en gradient and topographic order in retinotectal projection. Neuron 8, 787-798. doi: 90099-Y

10.1016/0896-6273(92)

Itoh, N., and Ornitz, D. M. (2004). Evolution of the Fgf and Fgfr gene families. Trends Genet. 20, 563-569. doi: 10.1016/j.tig.2004.08.007

Joyner, A. L. (1996). Engrailed, Wnt and Pax genes regulate midbrain-hindbrain development. Trends Genet. 12, 15-20. doi 10.1016/0168-9525(96)81383-7

Joyner, A. L., Herrup, K., Auerbach, B. A., Davis, C. A., and Rossant, J. (1991). Subtle cerebellar phenotype in mice homozygous for a targeted deletion of the En-2 homeobox. Science 251, 1239-1243. doi: 10.1126/science. 1672471

Joyner, A. L., Liu, A., and Millet, S. (2000). Otx2, Gbx2 and Fgf8 interact to position and maintain a mid-hindbrain organizer. Curr. Opin. Cell Biol. 12, 736-741. doi: 10.1016/S0955-0674(00)00161-7

Joyner, A. L., and Sudarov, A. (2012). "Genetic Neuroanatomy," in The Mouse Nervous System, eds C. Watson, G. Paxinos, and L. Puelles (London: Academic Press), 36-50. doi: $\quad$ 10.1016/B978-0-12-3694973.10003-2

Katahira, T., Sato, T., Sugiyama, S., Okafuji, T., Araki, I., Funahashi, J. et al. (2000). Interaction between Otx2 and Gbx2 defines the organizing center for the optic tectum. Mech. Dev. 91, 43-52. doi 10.1016/S0925-4773(99)00262-2

Koirala, S., and Corfas, G. (2010). Identification of novel glial genes by single-cell transcriptional profiling of Bergmann glial cells from mouse cerebellum. PLoS ONE 5:e9198. doi: 10.1371/journal.pone.0009198
Lainé, J., and Axelrad, H. (1994). The candelabrum cell: a new interneuron in the cerebellar cortex. J. Comp. Neurol. 339, 159-173. doi: 10.1002/cne. 903390202

Lancioni, A., Pizzo, M., Fontanella, B., Ferrentino, R., Napolitano, L. M., De Leonibus, E., et al. (2010). Lack of Mid1, the mouse ortholog of the Opitz syndrome gene, causes abnormal development of the anterior cerebellar vermis. J. Neurosci. 30, 2880-2887. doi: 10.1523/JNEUROSCI.4196-09.2010

Leto, K., Carletti, B., Williams, I. M., Magrassi, L., and Rossi, F. (2006). Different types of cerebellar GABAergic interneurons originate from a common pool of multipotent progenitor cells. J. Neurosci. 26, 11682-11694. doi: 10.1523/JNEUROSCI.3656-06.2006

Li, J. Y., and Joyner, A. L. (2001). Otx2 and Gbx2 are required for refinement and not induction of mid-hindbrain gene expression. Development 128, 4979-4991.

Liu, A., and Joyner, A. L. (2001). EN and GBX2 play essential roles downstream of FGF8 in patterning the mouse mid/hindbrain region. Development 128, 181-191.

Mareš, V., Lodin, Z., and SØajer, J. (1970). The cellular kinetics of the developing mouse cerebellum. I. The generation cycle, growth fraction and rate of proliferation of the external granular layer. Brain Res. 23, 323-342. doi: 10.1016/00068993(70)90060-0

Marin, F., and Puelles, L. (1994). Patterning of the embryonic avian midbrain after experimental inversions: a polarizing activity from the isthmus. Dev. Biol. 163, 19-37. doi: 10.1006/dbio.1994.1120

Marín, F., and Puelles, L. (1995). Morphological fate of rhombomeres in quail/chick chimeras: a segmental analysis of hindbrain nuclei. Eur. J. Neurosci. 7, 1714-1738. doi: 10.1111/j.14609568.1995.tb00693.x

Martínez, S. (2001). The isthmic organizer and brain regionalization. Int J. Dev. Biol. 45, 367-371.

Martinez, S., and Alvarado-Mallart, R. M. (1989). Rostral cerebellum originates from the caudal portion of the so-called 'mesencephalic' vesicle: a study using chick/quail chimeras. Eur. J. Neurosci. 1, 549-560. doi: 10.1111/j.14609568.1989.tb00362.x

Martinez, S., Crossley, P. H., Cobos, I. Rubenstein, J. L., and Martin, G. R. (1999). FGF8 induces formation of an ectopic isthmic organizer and isthmocerebellar development via a 
repressive effect on Otx2 expression. Development 126, 1189-1200.

Martínez, S., and Puelles, L. (2000). Neurogenetic compartments of the mouse diencephalon and some characteristic gene expression. Results Probl. Cell Differ. 30, 91-106. doi: 10.1007/978-3-540-48002-0_4

Martínez, S., Puelles, E., Puelles, L., and Echevarria, D. (2012). "Molecular regionalization of the developing neural tube" in The Mouse Nervous System, eds C. Watson, G. Paxinos, and L. Puelles (London: Academic Press), 2-18. doi: 10.1016/B978-012-369497-3.10001-9

Martinez, S., Wassef, M., and AlvaradoMallart, R. M. (1991). Induction of a mesencephalic phenotype in the 2-day-old chick prosencephalon is preceded by the early expression of the homeobox gene engrailed. Neuron 6, 971-981. doi: 10.1016/0896-6273(91)90237-T

Martinez-Barbera, J. P., Signore, M., Boyl, P. P., Puelles, E., Acampora, D., Gogoi, R., et al. (2001). Regionalisation of anterior neuroectoderm and its competence in responding to forebrain and midbrain inducing activities depend on mutual antagonism between OTX2 and GBX2. Development 128, 4789-4800.

Matsunaga, E., Katahira, T., and Nakamura, H. (2002). Role of Lmxlb and Wntl in mesencephalon and metencephalon development. Development 129, 5269-5277.

Meinhardt, H. (1983). Cell determination boundaries as organizing regions for secondary embryonic fields. Dev. Biol. 96, 375-385. doi: 10.1016/0012-1606(83)90175-6

Millen, K. J., and Gleeson, J. G. (2008). Cerebellar development and disease. Curr. Opin. Neurobiol. 18, 12-19. doi: 10.1016/j.conb.2008.05.010

Millen, K. J., Millonig, J. H., Wingate, R. J., Alder, J., and Hatten, M. E. (1999). Neurogenetics of the cerebellar system. J Child Neurol. 14, 574-581. doi: 10.1177/08830738990 1400905

Millen, K. J., Hui, C. C., and Joyner, A. L. (1995). A role for En-2 and other murine homologues of Drosophila segment polarity genes in regulating positional information in the developing cerebellum. Development 121 , 3935-3945.

Millet, S., Bloch-Gallego, E., Simeone, A., and Alvarado-Mallart, R. M. (1996). The caudal limit of Otx2 gene expression as a marker of the midbrain/hindbrain boundary: a study using in situ hybridisation and chick/quail homotopic grafts. Development 122 , 3785-3797.

Millet, S., Campbell, K., Epstein, D. J., Losos, K., Harris, E., and Joyner, A. L. (1999). A role for Gbx2 in repression of Otx2 and positioning the mid/hindbrain organizer. Nature 401, 161-164. doi: $10.1038 / 43664$

Minaki, Y., Nakatani, T., Mizuhara, E., Inoue, T., and Ono, Y. (2008). Identification of a novel transcriptional corepressor, Corl2, as a cerebellar Purkinje cell-selective marker. Gene Expr. Patterns 8, 418-423. doi: 10.1016/j.gep.2008.04.004

Minowada, G., Jarvis, L. A., Chi, C. L., Neubüser, A., Sun, X., Hacohen, N., et al. (1999). Vertebrate Sprouty genes are induced by FGF signaling and can cause chondrodysplasia when overexpressed. Development 126, 4465-4475.

Mizuhara, E., Minaki, Y., Nakatani, T., Kumai, M., Inoue, T., Muguruma, K., et al. (2010). Purkinje cells originate from cerebellar ventricular zone progenitors positive for Neph3 and E-cadherin. Dev. Biol. 338, 202-214. doi: 10.1016/j.ydbio. 2009.11.032

Muguruza, K., and Sasai, Y. (2012). In vitro recapitulation of neural development using embryonic stem cells: from neurogenesis to histogenesis. Dev. Growth Differ. 54, 349-357. doi: 10.1111/j.1440-169X.2012.01329.x

Müller, P., Rogers, K. W., Yu, S. R., Brand, M., and Schier, A. F. (2013). Morphogen transport. Development 140, 1621-1638. doi: 10.1242/dev.083519

Nakamura, H., Katahira, T., Matsunaga, E., and Sato, T. (2005). Isthmus organizer for midbrain and hindbrain development. Brain Res. Brain Res. Rev. 49, 120-126. doi: 10.1016/j.brainresrev.2004.10.005

Nicolson, R., Fawcett, A. J., and Dean, P. (2001). Dyslexia, development and the cerebellum. Trends Neurosci. 24, 515-516. doi: 10.1016/S01662236(00)01923-8

Nowak, M., Machate, A., Yu, S. R., Gupta, M., and Brand, M. (2011). Interpretation of the FGF8 morphogen gradient is regulated by endocytic trafficking. Nat. Cell Biol. 13, 153-158. doi: 10.1038/ncb2155

Orvis, G. D., Hartzell, A. L., Smith, J. B., Barraza, L. H., Wilson, S. L., Szulc, K. U., et al. (2012). The engrailed homeobox genes are required in multiple cell lineages to coordinate sequential formation of fissures and growth of the cerebellum. Dev. Biol. 367, 25-39. doi: 10.1016/j.ydbio.2012.04.018
Owens, D. G., Johnstone, E. C., Frith, C. D. (1982). Spontaneous involuntary disorders of movement: their prevalence, severity, and distribution in chronic schizophrenics with and without treatment with neuroleptics. Arch. Gen. Psychiatry 39, 452-461. doi: 10.1001/archpsyc. 1982.04290040052008

Partanen, J. (2007). FGF signalling pathways in development of the midbrain and anterior hindbrain. J. Neurochem. 101, 1185-1193. doi: 10.1111/j.1471-4159.2007.04463.x

Pascual, M., Abasolo, I., MingoranceLe Meur, A., Martínez, A., Del Rio, J. A., et al. (2007). Cerebellar GABAergic progenitors adopt an external granule cell-like phenotype in the absence of Ptfla transcription factor expression. Proc. Natl. Acad. Sci. U.S.A. 104, 5193-5198. doi: 10.1073/pnas.0605699104

Pinson, L., Augé, J., Audollent, S., Mattéi, G., Etchevers, H., Gigarel, N., et al. (2004). Embryonic expression of the human MID1 gene and its mutations in Opitz syndrome. J. Med. Genet. 41, 381-386. doi: 10.1136/jmg.2003.014829

Prakash, N., Brodski, C., Naserke, T., Puelles, E., Gogoi, R., Hall, A., et al. (2006). A Wntl-regulated genetic network controls the identity and fate of midbrain-dopaminergic progenitors in vivo. Development 133 , 89-98. doi: 10.1242/dev.02181

Prakash, N., and Wurst, W. (2006). Development of dopaminergic neurons in the mammalian brain. Cell Mol. Life Sci. 63, 187-206. doi: 10.1007/s00018-005-5387-6

Puelles, L. (1995). A segmental morphological paradigm for understanding vertebrateforebrains. Brain Behav. Evol. 46, 319-337. doi: 10.1159/000113282

Puelles, L., and Ferran, J. L. (2012). Concept of neural genoarchitecture and its genomic fundament. Front. Neuroanat. 6:47. doi: 10.3389/fnana. 2012.00047

Puelles, L., and Rubenstein, J. L. (2003). Forebrain gene expression domains and the evolving prosomeric model. Trends Neurosci. 26, 469-476. doi: $\quad 10.1016 /$ S0166-2236(03) 00234-0

Quaderi, N. A., Schweiger, S., Gaudenz, K., Franco, B., Rugarli, E. I., Berger, W., et al. (1997). Opitz G/BBB syndrome, a defect of midline development, is due to mutations in a new RING finger gene on Xp22. Nat. Genet. 17, 285-291. doi: 10.1038/ng1197-285

Rakic, P. (1990). Principles of neural cell migration. Experientia 46, 882-891. doi: 10.1007/BF01939380
Rhinn, M., and Brand, M. (2001). The midbrain-hindbrain boundary organizer. Curr. Opin. Neurobiol. 11, 34-42. doi: 10.1016/S0959-4388 (00)00171-9

Rio, C., Rieff, H. I., Qi, P., Khurana, T. S., and Corfas, G. (1997) Neuregulin and erbB receptors play a critical role in neuronal migration. Neuron 19, 39-50. doi: 10.1016/S0896-6273(00)80346-3

Rogers, T. D., McKimm, E., Dickinson, P. E., Goldowitz, D., Blaha, C. D. and Mittleman, G. (2013). Is autism a disease of the cerebellum. An integration of clinical and pre-clinical research. Front. Syst. Neurosci. 7:15. doi: 10.3389/fnsys.2013.00015

Rong, Y., Wang, T., and Morgan, J. I. (2004). Identification of candidate Purkinje cell specific markers by gene expression profiling in wild-type and pcd3J mice. Mol. Brain Res. 132, 128-145. doi: 10.1016/j.molbrainres.2004.10.015

Rowitch, D. H., and McMahon, A. P. (1995). Pax-2 expression in the murine neural plate precedes and encompasses the expression domains of Wnt-1 and En-1. Mech. Dev. 52, 3-8. doi: 10.1016/0925-4773(95)00380-J

Rubenstein, J. L., and Puelles, L. (1994). Homeobox gene expression during development of the vertebrate brain. Curr. Top. Dev. Biol. 29, 1-63. doi: 10.1016/S0070-2153(08)60546-3

Rubenstein, J. L., Shimamura, K., Martinez, S., and Puelles, L. (1998). Regionalization of the prosencephalic neural plate. Annu. Rev. Neurosci. 21, 445-477. doi: 10.1146/annurev.neuro.21.1.445

Ruiz i Altaba, A. (1998). Neural patterning. Deconstructing the organizer. Nature 391, 748-749. doi: $10.1038 / 35761$

Sgaier, S. K., Lao, Z., Villanueva, M. P., Berenshteyn, F., Stephen, D., Turnbull, R. K., et al. (2007). Genetic subdivision of the tectum and cerebellum into functionally related regions based on differential sensitivity to engrailed proteins. Development 134, 2325-2335. doi: 10.1242/dev.000620

Sgaier, S. K., Millet, S., Villanueva, M. P., Berenshteyn, F., Song, C., and Joyner, A. L. (2005). Morphogenetic and cellular movements that shape the mouse cerebellum; insights from genetic fate mapping. Neuron 45, 27-40. doi: 10.1016/j.neuron.2004. 12.021

Shamim, H., and Mason, I. (1998). Expression of Gbx-2 during early development of the chick embryo. Mech. Dev. 76, 157-159. doi: 10.1016/S0925-4773(98)00102-6 
Shimamura, K., Hartigan, D. J., Martínez, S., Puelles, L., and Rubenstein, J. L. (1995). Longitudinal organization of the anterior neural plate and neural tube. Development 121, 3923-3933.

Sotelo, C. (2004). Cellular and genetic regulation of the development of the cerebellar system. Prog. Neurobiol. 72, 295-339. doi: 10.1016/j.pneurobio.2004.03.004

Soto-Ares, G., Joyes, B., Lemaître, M. P., Vallée, L., and Pruvo, J. P. (2003). MRI in children with mental retardation. Pediatr. Radiol. 33, 334-345. Spemann, H., and Mangold, H. (1924). über Induktion von Embryonalanlagen durch Implantation artfremder Organisatoren. Dev. Genes Evol. 100, 599-638.

Sudarov, A., and Joyner, A. L. (2007). Cerebellum morphogenesis: the foliation pattern is orchestrated by multi-cellular anchoring centers. Neural Dev. 3, 2-26. doi: 10.1186/ 1749-8104-2-26

Sunmonu, N. A., Li, K., Guo, Q., and Li, J. Y. (2011). Gbx2 and Fgf8 are sequentially required for formation of the midbrainhindbrain compartment boundary. Development 138, 725-734. doi: 10.1242/dev.055665

Suzuki, A., Harada, H., and Nakamura, H. (2012). Nuclear translocation of FGF8 and its implication to induce Sprouty2. Dev. Growth Differ. 54, 463-473. doi: 10.1111/j.1440-169X.2012.01332.x

Tsang, M., Friesel, R., Kudoh, T., and Dawid, I. B. (2002). Identification of Sef, a novel modulator of FGF signalling. Nat. Cell Biol. 4, 165-169. doi: $10.1038 /$ ncb749

Tvrdik, P., and Capecchi, M. R. (2012). "Gene targeting" in The Mouse Nervous System, eds C. Watson, G. Paxinos, and L. Puelles (London: Academic Press), 19-35. doi: $\quad$ 10.1016/B978-0-12-3694973.10002-0
Vaage, S. (1969). The segmentation of the primitive neural tube in chick embryos (Gallus domesticus). A morphological, histochemical and autoradiographical investigation. Ergeb. Anat. Entwicklungsgesch. 41, 3-87.

Vieira, C., Garcia-Lopez, R., and Martínez, S. (2006). Positional regulation of Pax2 expression pattern in mesencephalic and diencephalic alar plate. Neuroscience 137, 7-11. doi: 10.1016/j.neuroscience.2005. 09.017

Vieira, C., Pombero, A., García-Lopez, R., Gimeno, L., Echevarria, D., and Martínez, S. (2010). Molecular mechanisms controlling brain development: an overview of neuroepithelial secondary organizers. Int. J. Dev. Biol. 54, 7-20. doi: $10.1387 / \mathrm{ijdb} .092853 \mathrm{cv}$

Vogel-Höpker, A., and Rohrer, H. (2002). The specification of noradrenergic locus coeruleus (LC) neurones depends on bone morphogenetic proteins (BMPs). Development 129, 983-991.

Wang, V. Y., Rose, M. F., and Zoghbi, H. Y. (2005). Math1 expression redefines the rhombic lip derivatives and reveals novel lineages within the brainstem and cerebellum. Neuron 48, 31-43. doi: 10.1016/j.neuron.2005.08.024

Wang, V. Y., and Zoghbi, H. Y. (2001). Genetic regulation of cerebellar development. Nat. Rev. Neurosci. 2, 484-491. doi: 10.1038/35081558

Wassarman, K. M., Lewandoski, M., Campbell, K., Joyner, A. L., Rubenstein, J. L., Martinez, S. et al. (1997). Specification of the anterior hindbrain and establishment of a normal mid/hindbrain organizer is dependent on Gbx2 gene function. Development 124, 2923-2934.

Wassef, M., and Joyner, A. L. (1997). Early mesencephalon/ metencephalon patterning and development of the cerebellum. Perspect. Dev. Neurobiol. 5, 3-16.

Wingate, R. J. (2001). The rhombic lip and early cerebellar development. Curr. Opin. Neurobiol. 11, 82-88. doi: $\quad 10.1016 /$ S0959-4388(00) 00177-X

Wurst, W., and Bally-Cuif, L. (2001). Neural plate patterning: upstream and downstream of the isthmic organizer. Nat. Rev. Neurosci. 2, 99-108. doi: 10.1038/35053516

Xu, J., Liu, Z., and Ornitz, D. M. (2000). Temporal and spatial gradients of Fgf8 and Fgf17 regulate proliferation and differentiation of midline cerebellar structures. Development 127, 1833-1843.

Yamada, K., Fukaya, M., Shibata, T., Kurihara, H., Tanaka, K., Inoue, Y., et al. (2000). Dynamic transformation of Bergmann glial fibers proceeds in correlation with dendritic outgrowth and synapse formation of cerebellar Purkinje cells. J. Comp. Neurol. 418, 106-120. doi: 10.1002/(SICI)1096 9861(20000228)418:1<106::AID$\mathrm{CNE} 8>3.0 . \mathrm{CO} ; 2-\mathrm{N}$

Yamada, K., and Watanabe, M. (2002). Cytodifferentiation of Bergmann glia and its relationship with Purkinje cells. Anat. Sci. Int. 77, 94-108. doi: 10.1046/j.0022-7722.2002.00021.x

Yu, S. R., Burkhardt, M., Nowak, M., Ries, J., Petrásek, Z., Scholpp, S., et al. (2009). Fgf8 morphogen gradient forms by a sourcesink mechanism with freely diffusing molecules. Nature 461, 533-536. doi: 10.1038/nature 08391

Zanni, G., Barresi, S., Travaglini, L., Bernardini, L., Rizza, T., Digilio, M. C., et al. (2011). FGF17, a gene involved in cerebellar development, is downregulated in a patient with Dandy-Walker malformation carrying a de novo $8 \mathrm{p}$ deletion. Neurogenetics 12,
241-245. doi: 10.1007/s10048-0110283-8

Zervas, M., Blaess, S., and Joyner, A. L. (2005). Classical embryological studies and modern genetic analysis of midbrain and cerebellum development. Curr. Top Dev. Biol. 69, 101-138. doi: $\quad 10.1016 /$ S0070-2153(05) 69005-9

Zhao, R., Lawler, A. M., and Lee, S. J. (1999). Characterization of GDF10 expression patterns and null mice. Dev. Biol. 212, 68-79. doi: 10.1006/dbio.1999.9326

Zordan, P., Croci, L., Hawkes, R., and Consalez, G. G. (2008). Comparative analysis of proneural gene expression in the embryonic cerebellum. Dev. Dyn. 237, 1726-1735. doi: $10.1002 /$ dvdy.21571

Conflict of Interest Statement: The authors declare that the research was conducted in the absence of any commercial or financial relationships that could be construed as a potential conflict of interest.

Received: 26 March 2013; paper pending published: 09 April 2013; accepted: 03 June 2013; published online: 26 June 2013.

Citation: Martinez S, Andreu A, Mecklenburg $N$ and Echevarria $D$ (2013) Cellular and molecular basis of cerebellar development. Front. Neuroanat. 7:18. doi: 10.3389/fnana. 2013.00018

Copyright (c) 2013 Martinez, Andreu, Mecklenburg and Echevarria. This is an open-access article distributed under the terms of the Creative Commons Attribution License, which permits use, distribution and reproduction in other forums, provided the original authors and source are credited and subject to any copyright notices concerning any thirdparty graphics etc. 